\title{
Industrialization of LHC Main Quadrupole Cold Masses Up to Series Production
}

\author{
Rolf Burgmer, Detlef Krischel, Udo Klein, Kurt Knitsch, Paul Schmidt, Theodor Tortschanoff, Karl Schirm, \\ Maria Durante, Jean Michel Rifflet, and Fabrice Simon
}

\begin{abstract}
Whereas the prototypes of the main quadrupoles had been pursued at CEA Saclay under contract with CERN, the contract to build all MQ magnets and the complete cold masses had been placed with ACCEL Instruments GmbH. After careful evaluation of design concepts and fabrication processes some revisions have been introduced to ease an industrial fabrication of the 400 MQ magnets and cold masses to be delivered to CERN. First batches of magnets were successfully cold tested. We report about the upgrading of the fabrication facility including the MQ specific layout of all machinery, the upgrading and qualifying of personnel resources and processes, the technical performance of the products and main activities and experiences on the way to series production.
\end{abstract}

Index Terms-Industrialization, LHC, main quadrupoles, superconducting magnets.

\section{INTRODUCTION}

A CCEL is an experienced designer and an industrial manufacturer of superconducting magnets (e.g., HERA, SSC, LHC prototypes MQM, MQT) [1], [2]. In July 2000 ACCEL won a contract to produce the 400 Main Quadrupole (MQ) magnets and cold masses for the LHC project at CERN. In addition ACCEL is also fabricating the MQY magnets [4].

\section{First Activities Before AND AfTER AWARD OF CONTRACT}

\section{A. Evaluation of Design and Processes}

The design and the assembly procedures of the MQ magnets and cold masses were developed by CEA Saclay and successfully tested during the prototype phase [3]. Therefore detailed information was available during the tender phase. ACCEL analyzed thoroughly if the specified design and processes met the requirements of industrial manufacturing standards with regard to e.g., ease of production of component, production (tool) complexity and manufacturing costs. After evaluation most of the main design features and procedures were adopted for series production.

One major production step was changed: the collar key design and the keying procedure of the collared coil was suggested to be modified from a 3-piece to a 1-piece key to facilitate series

Manuscript received October 20, 2003

R. Burgmer, D. Krischel, U. Klein, K. Knitsch, and P. Schmidt are with ACCEL Instruments GmbH, Germany (e-mail: schmidt@accel.de).

T. Tortschanoff and K. Schirm are with CERN, LHC Devision, Geneva, Swiss

M. Durante, J. M. Rifflet, and F. Simon are with CEA Saclay, France.

Digital Object Identifier 10.1109/TASC.2004.829035 production. After award of contract CERN/CEA agreed to evaluate the suggestion in a mock up test (see chapter III).

\section{B. Simulation of Fabrication}

The series production of MQ magnets and cold masses has been simulated with appropriate computer programs. Basis for the simulation was a detailed work break down structure and meticulous assessment of the duration of the single process steps. The results were used for assessment of kind and number of tools, the size of the needed production work shop and for the profession and number of personnel.

\section{Refurbishing of Facility}

The existing work shop floor space was occupied with projects in progress. Already before award of contract ACCEL reserved the right of renting an old fabrication hall of $2500 \mathrm{sqm}$ with the option on an adjacent hall of $1800 \mathrm{sqm}$, to be prepared for a 200 magnet/cold masses or 400 magnet/cold masses contract. After award of the contract to produce $100 \%$ of the 400 MQ magnets and cold masses ACCEL rented both halls. Both halls received intense refurbishing work and have been converted into state of the art production facilities for superconducting magnets.

\section{Layout of Fabrication and Order of Tools}

The results of the simulation of the fabrication were adapted to the available space of the fabrication halls. The major guideline of the layout was the optimization of flow of material and processes. Respective processes were grouped in working stations: coil production, aperture production, magnet production, vertical assembly of cold mass, horizontal assembly of cold mass and He-leak test. In addition appropriate areas were assigned for incoming goods, storage of components, offices etc. The long lead tools were identified and ordered and the auxiliary equipment designed and ordered.

\section{E. Order of Components}

Approximately 15000 parts have to be assembled by hand to produce a single MQ cold mass. These parts were combined into appropriate component groups, orders negotiated and placed with about 30 main subsuppliers.

\section{F. Human Resources}

Immediately after award of the LHC MQ contract ACCEL launched a program for hiring and qualifying dedicated personnel. This included not only mechanics for the production of 
Collaring test at ACCEL (20/11/2001)

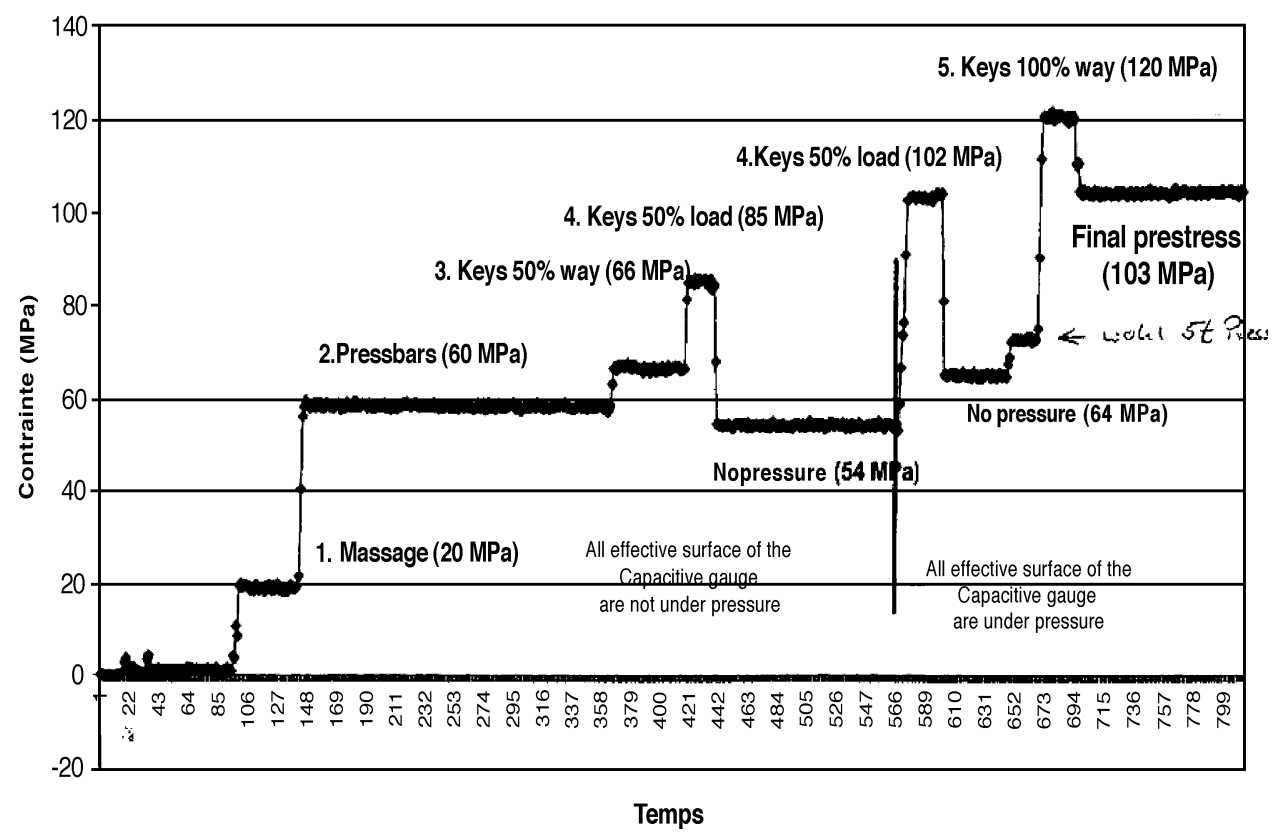

Fig. 1. Collaring test at ACCEL.

magnets and cold masses but also welders, quality assurance technicians and staff to operate the facility in general.

\section{START OF FABRICATION}

\section{A. Tests of Sensitive Fabrication Steps}

Detailed process plans for each working station were written by ACCEL based on the CEA prototype experience. The prototype equipment was installed in the ACCEL halls and with remainders of the prototype components, sensitive fabrication steps could be tested under guidance of CEA technicians [5], e.g., the coil winding which is one of the most critical working steps. In these tests the winding processes were practiced and qualified and auxiliary equipment, important to facilitate the work while assuring the quality, was designed, ordered and qualified, e.g., holders for end spacers during winding. After the ACCEL designed collaring press had been installed several mock up tests were performed to verify the ACCEL concept for keying of the collared coils. This concept is based on 1-piece key inserted by a multi-press cylinder collaring press in 4 defined press processes. These tests demonstrated that the goal of applying 80-100 MPa prestress in the coils could be achieved without exceeding the maximum allowed pressure on the conductor during the keying process or deforming the keys, Fig. 1.

\section{B. Production of First MQ Magnet}

After reception of the first components and installation of all necessary equipment the production of the main components started: coils, apertures, magnets. The first magnet was completed in July 2002. The total production time of this first magnet stretched over almost 6 months. This was mostly due to numerous trials to cure to the required coil size and to qualify subsupplier components to achieve the tight tolerances. The second magnet was finished one month after the first. Both magnets passed the cold acceptance tests at CERN with excellent results as indicated in Fig. 2.

\section{Production of First Cold Mass}

The cold masses are made up of the $3.2 \mathrm{~m}$ long yoked " 2 in 1"-MQ-magnets plus different types of corrector magnets to be assembled on both sides of the MQ. After busbar assembly and all electrical wiring the cold masses are completed by integration of the magnets into more than 6 meter long inertia tubes which serve as helium vessel. The assembly of the first cold mass was prepared by assembling an empty helium vessel (so called dummy cold mass). This step was essential to test and demonstrate the welding procedures and especially to qualify the highly sophisticated dimensional controls with the laser tracker system, Fig. 3. The first cold mass was completed in Jan. 2003 and delivered to CERN. In the meantime it has been installed into a cryostat at CERN and passed the cold acceptance tests very successfully.

\section{RAMPING Up to SERIES PRODUCTION}

\section{A. Installation of Series Production Tools}

The time of producing the first magnets and cold masses had been used to install the tools and equipment for series production. Fig. 4 shows hall 1 which is dedicated to the production of coils and apertures while in hall 2 the magnets and the cold masses are assembled.

\section{B. Qualification of Tools and Fine Tuning of Procedures}

To meet the requirement of reproducibility each tool had to undergo a qualification program. The coils for example should 


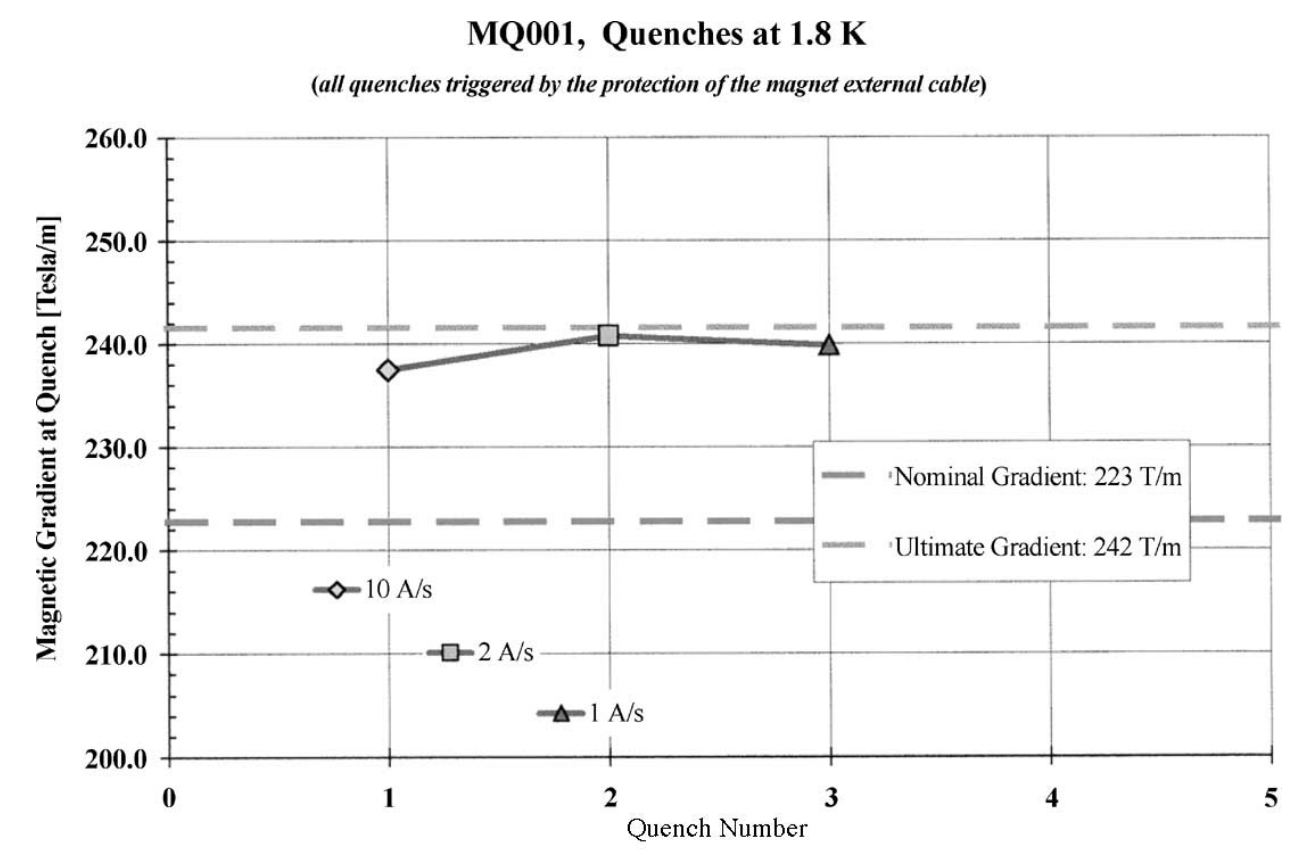

Fig. 2. Results of cold tests of first MQ magnet.

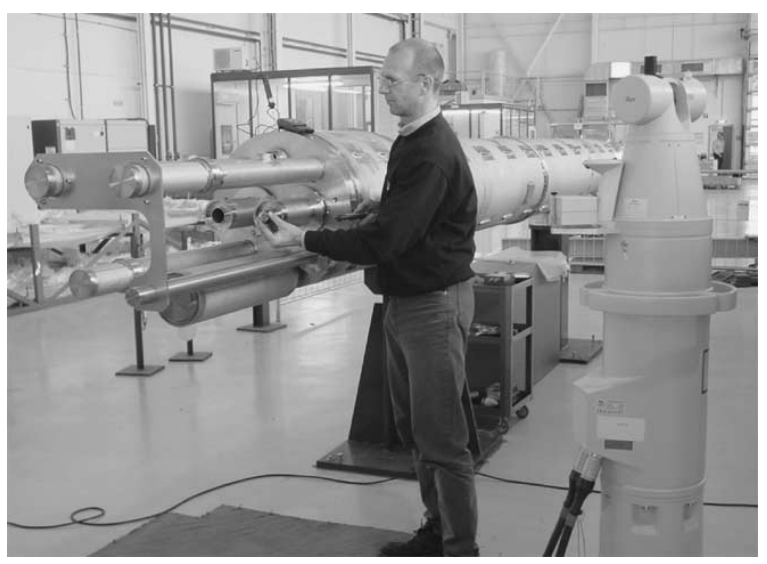

Fig. 3. Mechanical measurement of coil mass with laser tracker system.

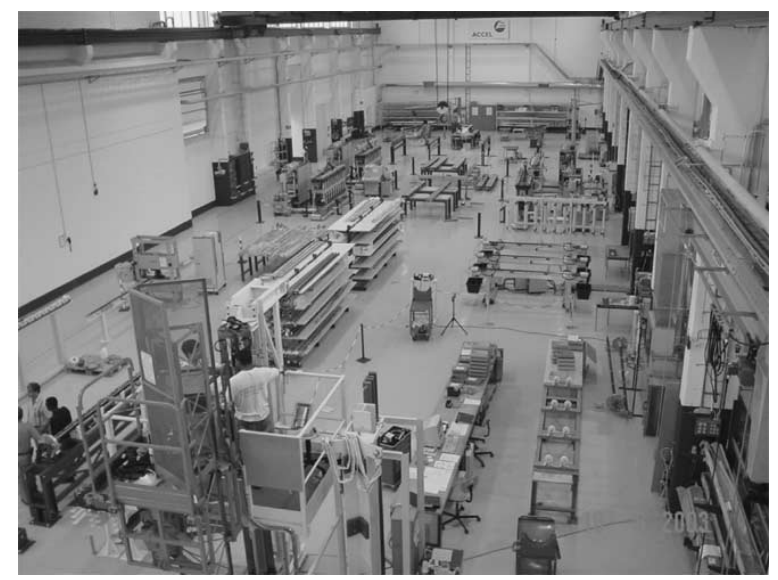

Fig. 4. ACCEL magnet fabrication hall 1.

have exactly the same dimensions within a few hundreds of millimeter independent of the production tool. This meant that 2 winding machines, 8 winding mandrels, 4 curing presses and
8 curing moulds had to be qualified. Especially the fine tuning of the curing presses was very time consuming. In addition analyzes of the process flow revealed some bottle necks in production which could be eliminated by changes in process (e.g., forming of coil interlayer insulation) or multiplying of tools for parallel work (e.g., head impregnation station).

\section{Hiring and Qualification of Mechanics and Staff}

Parallel to the installation of tools additional personnel had to be hired and qualified. According to the grouping of the production into working stations personnel were assigned to a working station and trained.

\section{Analyzes of Efficiency of Processes}

During the process of ramping up to series production rate the manufacturing procedures have been analyzed to see if the actual production rates meet the predicted goals. Detailed investigations of the less efficient processes revealed different reasons for deviations leading to appropriate solutions. The many working steps e.g., for producing coils have to be reorganized from serial into parallel work by separating the winding of coils and auxiliary work. For building apertures e.g. the unexpected long soldering time of the connection box requires a second soldering stand and double shift work.

\section{E. Computerized Production Planning System}

A computerized production planning system was implemented. This system controls the production by only allowing the sequence of working steps according to the process plans including the required tests and checks. In addition the system serves as data acquisition system for all data required to be transferred to CERN. After several adjustments the system is now in full operation for producing magnets. The data transfer will be discussed and determined with CERN/CEA in the next months. 


\section{MAIN EXPERIENCES AND LESSONS LEARNED}

\section{A. Tight Tolerances}

The MQ project is characterized by extremely tight tolerances as it is standard for the production of this kind of magnets as well as for their manufacturing procedures. Some component subsuppliers still have difficulties in meeting the tolerance requirements constantly during series production. This leads to additional tests during incoming inspection. On the other hand the manufacturing tolerances of the inertia tube e.g., are in the same range as the measurement tolerances of the laser tracker systems leading to lengthy evaluations of measurement data. After collecting enough test results and manufacturing experience one should consider if in some cases larger tolerances are acceptable.

\section{B. Reproducibility}

Repeatedly Young modulus measurements have been performed to control the mechanical and geometrical performance of the coils. In some cases differences in coil thickness have been observed Many possible reasons like deviations in component dimensions, tool performance or deficiencies in automatic or manual procedures have been investigated without having found an explanation yet. Currently the insulation of the cable is going to be investigated with regard to homogeneous thickness.

\section{Documentation}

For the first magnets and cold masses a huge amount of production and measurement data were collected and recorded in documentation files. After successful installation of a certain number of cold masses and after the evaluation of cold tests the required documentation should be limited to the necessary amount.

\section{Machine Break Down}

The production was several times slowed down by unexpected break downs of tools and machines. E.g., curing moulds (too high stress due to limited shrinkage after many load cycles), E-modulus machine (extremely high forces on the shaft by failure in the measurement control system), control systems of the prototype equipment and their software and hardware (10-15 years old). These problems were solved by appropriate measures. As a general prevention ACCEL is building up redundancies for sensitive machines and stocking up spare parts.

\section{E. Soldering of Busbars}

The requirement of acid free soldering flux after start of production and the delivery of oxidized busbar connections led to unexpected problems in all soldering procedures. After numerous tests and trials an inductive soldering equipment with special auxiliary soldering moulds delivered satisfying results. But the process time is 10 times higher than anticipated.

\section{CONCLUSION}

Up to now more than 500 coils, 100 apertures, 40 magnets and 20 cold masses have been manufactured. All magnets and cold masses which have been cold-tested so far met the requirements of the specification and demonstrated an excellent performance. ACCEL has installed all necessary machines, procedures and personnel organizations and is now in the final stage of ramping up to series production.

\section{REFERENCES}

[1] A. Hobl, D. Krischel, and M. Schillo et al., "Performance of the single and twin-aperture models of the $6 \mathrm{kA}$ superconducting quadrupole (MQM) for the LHC insertion," IEEE Trans. Appl. Superconductivity, vol. 11, no. 1, pp. 1645-1648, March 2001.

[2] A. Hobl and D. Krischel et al., "Development of tuning quadrupole (MQT) prototype magnets for LHC," IEEE Trans. Appl. Superconductivity, vol. 12, no. 1, pp. 35-38, March 2002.

[3] G. Kirby, R. Burgmer, D. Krischel, and P. Schmidt, "Fabrication of the Pre-Series Wide Aperture Superconducting Quadrupoles for the LHC Insertions,", this conference.

[4] M. Peyrrot, J. M. Rifflet, F. Simon, T. Tortschanoff, and P. Vedrine, "Construction of the new prototype of main quadrupole cold masses for the straight section of LHC," IEEE Trans. Appl. Superconductivity, vol. 10, no. 1, pp. 170-173, March 2000.

[5] T. Tortschanoff, R. Burgmer, D. Krischel, M. Peyrot, J. M. Rifflet, P. Schmidt, and F. Simon, "Launching of series fabrication of LHC main quadrupoles," IEEE Trans. Appl. Superconductivity, vol. 12, no. 1, pp. 287-290, March 2002. 